\title{
Isolation and characterization of microsatellite markers for Sturnira parvidens and cross-species amplification in Sturnira species (\#16730)
}

First revision

Please read the Important notes below, the Review guidance on page 2 and our Standout reviewing tips on page 3 . When ready submit online. The manuscript starts on page 4.

Important notes

\section{Editor}

Erica Goss

Files

1 Tracked changes manuscript(s)

1 Rebuttal letter(s)

1 Figure file(s)

3 Table file(s)

1 Raw data file(s)

1 Other file(s)

Please visit the overview page to download and review the files not included in this review PDF.

Declarations

One or more DNA sequences were reported. Involves a field study on animals or plants. 
Please read in full before you begin

\section{How to review}

When ready submit your review online. The review form is divided into 5 sections. Please consider these when composing your review:

\section{BASIC REPORTING}

2. EXPERIMENTAL DESIGN

3. VALIDITY OF THE FINDINGS

4. General comments

5. Confidential notes to the editor

You can also annotate this PDF and upload it as part of your review

To finish, enter your editorial recommendation (accept, revise or reject) and submit.

\section{BASIC REPORTING}

Clear, unambiguous, professional English language used throughout.

Intro \& background to show context. Literature well referenced $\&$ relevant.

Structure conforms to PeerJ standards, discipline norm, or improved for clarity.

Figures are relevant, high quality, well labelled \& described.

Raw data supplied (see PeerJ policy).

\section{EXPERIMENTAL DESIGN}

Original primary research within Scope of the journal.

Research question well defined, relevant $\&$ meaningful. It is stated how the research fills an identified knowledge gap.

Rigorous investigation performed to a high technical \& ethical standard.

Methods described with sufficient detail \& information to replicate.

\section{VALIDITY OF THE FINDINGS}

Impact and novelty not assessed. Negative/inconclusive results accepted. Meaningful replication encouraged where rationale $\&$ benefit to literature is clearly stated.

Data is robust, statistically sound, $\&$ controlled.
Conclusions are well stated, linked to original research question \& limited to supporting results.

Speculation is welcome, but should be identified as such.

The above is the editorial criteria summary. To view in full visit https://peerj.com/about/editorialcriteria/ 
The best reviewers use these techniques

Tip

\author{
Support criticisms with \\ evidence from the text or from \\ other sources
}

\section{Give specific suggestions on how to improve the manuscript}

\section{Comment on language and grammar issues}

Organize by importance of the issues, and number your points

\section{Example}

Smith et al (J of Methodology, 2005, V3, pp 123) have shown that the analysis you use in Lines 241-250 is not the most appropriate for this situation. Please explain why you used this method.

Your introduction needs more detail. I suggest that you improve the description at lines 57- 86 to provide more justification for your study (specifically, you should expand upon the knowledge gap being filled).

The English language should be improved to ensure that your international audience can clearly understand your text. I suggest that you have a native English speaking colleague review your manuscript. Some examples where the language could be improved include lines 23, 77, 121, 128 - the current phrasing makes comprehension difficult.

1. Your most important issue

2. The next most important item

3. ...

4. The least important points

Line 56: Note that experimental data on sprawling animals needs to be updated. Line 66: Please consider exchanging "modern" with "cursorial".

I thank you for providing the raw data, however your supplemental files need more descriptive metadata identifiers to be useful to future readers. Although your results are compelling, the data analysis should be improved in the following ways: $A A, B B, C C$

I commend the authors for their extensive data set, compiled over many years of detailed fieldwork. In addition, the manuscript is clearly written in professional, unambiguous language. If there is a weakness, it is in the statistical analysis (as I have noted above) which should be improved upon before Acceptance.
Comment on strengths (as well as weaknesses) of the manuscript




\title{
Isolation and characterization of microsatellite markers for Sturnira parvidens and cross-species amplification in Sturnira species
}

\author{
Edgar G Gutiérrez ${ }^{1}$ ， Giovani Hernández Canchola ${ }^{2}$ ， Livia S León Paniagua ${ }^{2}$ ， Norberto Martínez Méndez ${ }^{1}$, \\ Jorge Ortega Corresp. 1 \\ ${ }^{1}$ Zoología, Instituto Politécnico Nacional /ENCB, CDMX, CDMX, México \\ 2 Biología Evolutiva, Facultad de Ciencias, UNAM, CDMX, CDMX, México \\ Corresponding Author: Jorge Ortega \\ Email address: artibeus2@aol.com
}

Background. Sturnira is one of the most species-rich genera in the Neotropics, and it is found from Mexico and the Lesser Antilles to Argentina. This genus forms a well-supported monophyletic clade with at least twenty-one recognized species, as well as several others under taxonomic review. Sturnira parvidens is a widespread frugivorous bat of the deciduous forests of the Neotropics, is highly abundant, and is a major component in fruit dispersal to regenerate ecosystems. Methods. We used a technique based on Illumina paired-end sequencing of a library highly enriched for microsatellite repeats to develop loci for $S$. parvidens. We analyzed millions of resulting reads with specialized software to extract those reads that contained di-, tri-, tetra-, penta-, and hexanucleotide microsatellites. Results. We selected and tested 14 polymorphic (di, tri, and tetra) microsatellites. All markers were genotyped on 26 different individuals from distinct locations of the disti tional area of S. parvidens. We observed medium-high genetic variation across most loci, but only 12 were functionally polymorphic. Levels of expected heterozygosity across all markers were high to medium (mean $\mathrm{H}_{\mathrm{E}}=0.79$, mean $\mathrm{H}_{\mathrm{O}}=$ 0.72). We pI :d ascertainment bias in twelve bats of the genus, obtaining null/monomorphic/polymorphic amplifications. Discussion. The Illumina paired-end sequencing system is capable of identifying massive numbers of microsatellite loci, while expending little time, reducing costs, and providing a large amount of data. The described polymorphic loci for $S$. parvidens in particular, and for the genus in general, could be suitable for further genetic analysis, including taxonomic inconsistencies, parentage/relatedness analysis, and population genetics assessments. 
1 Isolation and characterization of microsatellite markers for Sturnira parvidens and

2

3

4

5 cross-species amplification in Sturnira species Gutiérrez, E. G. ${ }^{a}$, G. Hernández-Canchola ${ }^{\mathrm{b}}$, L. León-Paniagua ${ }^{\mathrm{b}}$, N. Martínez-Méndez ${ }^{\mathrm{a}}$, and J. Ortega ${ }^{\mathrm{a}^{*}}$.

aZoología, Instituto Politécnico Nacional/ENCB, CDMX, CDMX, México.

Biología Evolutiva, Facultad de Ciencias, UNAM, CDMX, CDMX, México.

*corresponding author: Jorge Ortega e-mail: artibeus2@aol.com

Abstract

Background. Sturnira is one of the most species-rich genera in the Neotropics, and it is found from Mexico and the Lesser Antilles to Argentina. This genus forms a well-supported monophyletic clade with at least twenty-one recognized species, as well as several others under taxonomic review.

Sturnira parvidens is a widespread frugivorous bat of the deciduous forests of the Neotropics, is highly abundant, and is a major component in fruit dispersal to regenerate ecosystems. Methods. We used a technique based on Illumina paired-end sequencing of a library highly enriched for microsatellite repeats to develop loci for $S$. parvidens. We analyzed millions of resulting reads with specialized software to extract those reads that contained di-, tri-, tetra-, penta-, and hexanucleotide microsatellites.

Results. We selected and tested 14 polymorphic (di, tri, and tetra) microsatellites. All markers were genotyped on 26 different individuals from distinct locations of the distributional area of $S$. parvidens. We observed medium-high genetic variation across most loci, but only 12 were functionally polymorphic. Levels of expected heterozygosity across all markers were high to medium (mean $\mathrm{H}_{\mathrm{E}}=0.79$, mean $\mathrm{H}_{\mathrm{O}}=0.72$ ). We 
24 proved ascertainment bias in twelve bats of the genus, obtaining

25 null/monomorphic/polymorphic amplifications.

26 Discussion. The Illumina paired-end sequencing system is capable of identifying massive

27 numbers of microsatellite loci, while expending little time, reducing costs, and providing a

28 large amount of data. The described polymorphic loci for S. parvidens in particular, and

29 for the genus in general, could be suitable for further genetic analysis, including taxonomic

30 inconsistencies, parentage/relatedness analysis, and population genetics assessments.

\section{$31 \quad$ Introduction}

The yellow-shouldered Mesoamerican bat (Sturnira parvidens) is primarily associated with lower elevations ( 0 to $2000 \mathrm{~m}$ ), and is found mainly in tropical/subtropical habitats and ecotones (Villalobos \& Valerio 2002). S. parvidens is found from the northern Mexican Pacific Slope and the northern Mexican Gulf Slope southward to Northern Costa Rica, and including the Yucatan Peninsula (Hernández-Canchola \& León-Paniagua, submitted). S. parvidens has been caught in the understory and subcanopy of tropical and subtropical forests, in xeric scrubs, and in secondary and temperate forests. They are commonly found roosting in the foliage of forests of advanced successional stages, but their home ranges include mature and secondary forest (Evelyn \& Stiles, 2003). They mainly consume fruit from plants representing early stages of plant succession, like pioneer trees (Cecropia peltata), pioneer herbs (Solanum americanum, S. torvun, S. ochraceoferrugineum, Capsicum annuum), or pioneer shrubs (Piper hispidum, P. lapathifolium; Olea-Wagner et al., 2007). This frugivorous species is an important seed disperser, carrying out an important ecosystemic role in the restoration of secondary tropical forests. 
47 vulnerable to local extinction (Evelyn \& Stiles, 2003).

48

Pleistocene climatic oscillations and the complex orogeny of its distributional area shaped the phylogeography of this bat, generating two lowland lineages. The two genetic lineages, one in the Western Slope region of Mexico, and the other in the Eastern Slope region of Mexico and Central America, diverged into haplogroups around c. 0.423 Ma, and demographic expansion was detected later, after the splitting event (Hernández-Canchola \& León-Paniagua, submitted). Sturnira is the most speciose genus of frugivorous bats. Due to its ability to colonize new areas, it adapted to producing complex groups showing different genetic lineages (Velazco \& Patterson, 2013; 2014; Hernandez-Canchola \& León-Paniagua, submitted). The genus Stur. involves a highly diversified and complex group of species. This speciose group of bats inhabits the entire Neotropic realm and includes three mountain basal species: S. aratathomasi S. bidens, and S. nana. Also, it has been deseribed as a clade formed by species that usually inhabit highland mountain forests: S. bogotensis, S. burtonlimi, S. erythromos, S. hondurensis, S. koopmanhilli, S. ludovici, S. magna, S. mordax, S. oporaphilum, S. perla, S. tildae and S. adrianae (Velazco \& Patterson, 2013; Molinari et al., 2017). Lastly, it includes a group of species that inhabit lowland tropical forests: S. angeli, S. bakeri, S. lilium, S. luisi, S. new species 3, S. paulsoni, and S. parvidens (Velazco \& Patterson, 2013).

No developed microsatellite molecular markers are known for Sturnira parvidens; our goal was to isolate and characterize polymorphic microsatellite loci for the species by using Next-Generation Sequencing. The development of these markers can be useful for understanding the genetic structure of subpopulations in its distributional range. They can be used to identify the impact of humans on the fragmentation of the populations and 
assess the divergent lineages formed by the genetic drift. They can also be used to evaluate the inc $\bigcirc$ ual movements in the mosaic-fragmented landscapes, and discern the genetic component in the social structure of the population by assessing relatedness and paternity, ete. We prc $\bigcirc$ cross-species amplification in twelve species of the Sturnira genus, under the hypothesis of having a positive ascertainment bias due to the phylogenetic relatedness among species (Crawford et al., 1998; Li \& Kimmel, 2013). Suitable cross-species amplification will facilitate studies in Sturnira related bat populations of Middle and South America.

\section{Materials and Methods}

We obtained tissue samples from 26 distinct individuals of $S$. parvidens from different localities in its distributional range in Mexico. Specimens were provided by Colección de Mamíferos del Museo de Zoología "Alfonso L. Herrera”, Facultad de Ciencias-Universidad Nacional Autónoma de México. Tissue samples were stored individually in $95 \%$ ethanol until analysis. We followed the guidelines set forth by the American Society of Mammalogists for the use of wildlife (Gannon \& Sikes, 2007). Fieldwork was conducted with the permission of SEMARNAT (Secretaría del Medio Ambiente y Recursos Naturales de Mexico_- permit FAUT-0307). Six samples were sent to the Savannah River Ecology Laboratory, for an enrichment library process. The facility follows their own protocol and provides a database of the resulting microsatellites. Meanwhile the rest of the specimens were used to standardize protocols and assess polymorphism in microsatellites.

DNA was extracted following the instructions of the Qiagen protocol (Blood and Tissue Kit, Cat No. 69504) for shot-gun sequences, and we used the Universal Salt 
93 Protocol to extract DNA from the remaining specimens (Aljanabi \& Martinez, 1997). An

94 Illumina paired-end shotgun library was prepared by shearing $11 \mathrm{~g}$ of tissue DNA using a

95 Covaris S220 and following the standard protocol of the Illumina TruSeq DNA Library

96 Kit. Five million of the resulting reads were analyzed with the program PAL_

97 FINDER_v0.02.03 (Castoe et al., 2012), in order to extract those reads that contained di-, 98 tri-, tetra-, penta-, and hexanucleotide microsatellites.

Once positive reads were identified in PAL_FINDER, they were batched to a local

100 installation of the program MSATCOMMANDER v 0.8 .2 for primer design (Faircloth,

101 2008). We recovered 6790 unique loci (48 hexa, 97 penta, 1260 tetra, 1097 tri and 4288

102 dinucleotide-Figure 1), but only 14 were chosen for PCR trials that were performed in a 103 MultiGene ${ }^{\mathrm{TM}}$ Gradient Thermal Cycler (Labnet, Edison, NJ, USA). We directly labelled 104 forward primers (FAM) for each of the chosen loci. PCR reactions were performed in a 10 $105 \mu \mathrm{l}$ volume containing $30 \mathrm{ng}$ of DNA, $0.2 \mathrm{mM}$ of dNTPs, $10 \mathrm{mM}$ of each primer, $1 \mathrm{Taq}$ 106 buffer (Buffer PCR 10x), $0.3 \mu \mathrm{L} \mathrm{MgCl}_{2}(25 \mathrm{mM})$, and $1.0 \mathrm{U}$ of FlexiTaq polymerase. PCR 107 cycling conditions were as follows: initial denaturation at $95^{\circ} \mathrm{C}$ for $3 \mathrm{~min}$; followed by 30 cycles of $95^{\circ} \mathrm{C}$ for $3 \mathrm{~min}$, gradient temperature (ranging from 56 to $60{ }^{\circ} \mathrm{C}$ ) for $30 \mathrm{~s}$, and 72 ${ }^{\circ} \mathrm{C}$ for $2 \mathrm{~min}$; extension of $68^{\circ} \mathrm{C}$ for $8 \mathrm{~min}$; and final ending of $4{ }^{\circ} \mathrm{C}$. Exact annealing

110 temperatures for each primer are given in Table 1. We visualized the PCR products by 111 electrophoresis on $1.5 \%$ agarose gels. Markers were tested for amplification success, 112 polymorphism and specificity in 26 individuals of $S$. parvidens.

113 The results of the microsatellite profiles were examined using GeneMarker® v. 2.4.2 114 (SoftGenetics $\left.{ }^{\circledR}\right)$ and peaks were scored by hand. We obtained the number of homozygotes 115 and heterozygotes by scoring data. We estimated the proportion of polymorphic loci and 
116 the average number of alleles per locus by using the GDA software (Lewis \& Zaykin,

117 2001). We assessed the observed $\left(\mathrm{H}_{\mathrm{O}}\right)$ and the expected heterozygosity $\left(\mathrm{H}_{\mathrm{E}}\right)$, linkage

118 disequilibrium, and Hardy-Weinberg proportions by using Genepop 4.2 (Rousset, 2008),

119 and corroborated with Arlequin 3.5 (Excoffier, Laval \& Schneider, 2005). We used

120 MICROCHECKER to screen null alleles in each locus (van Oosterhout et al., 2004). We

121 measured polymorphic information content (PIC) with Cervus 3.0.7 (Kalinowski, Taper \&

122 Marshall, 2007).

123 We probed cross-species amplification in tissues of twelve species of the genus: $S$.

124 hondurensis, S. burtonlimi, S. oporaphilum, S. mordax, S. tildae, S. erythromos, S.

125 bogotensis, S. magna, S. new species 3, S. luisi, S. lilium, and S. bakeri (Supplemental

126 Information 1). All polymorphic loci were tested in the mentioned species by using similar

127 PCR conditions. We followed the ascertainment bias hypothesis of broad amplification in

128 similar phylogenetic species (Schlötterer, 2000).

$129 \quad$ Results

130 We obtained a total of 6790 potentially an $\bigcirc$ ed loci (PALs), containing perfect,

131 imperfect, and compound microsatellites (Figure 1). Dinucleotide microsatellites were the

132 most abundant (4288), followed by tetra (1260); hexa microsatellites were the least

133 abundant in our readings (48). PCR reactions showed that of the 14 loci tested, two were

134 non-specific or monomorphic, and only 12 loci were polymorphic such that we were able

135 to get proper amplification (Table 1). Annealing temperature ranged from 56 to $60{ }^{\circ} \mathrm{C}$.

136 We found moderate levels of allelic richness, with an average of 8.8 alleles per locus

137 in the representative selection from the wide area of ${ }^{\circ}$ listribution. Polymorphic

138 information content (PIC) presented values above 0.5 showing a significant content of 
139

140

141

142

143

144

145

146

147

148

150

151

152

153

154

155

156

157

158

159

160

161

alleles per locus. Allele frequencies showed a remarkable ni 2 ar of alleles per locus, driving a superior number of valuable loci to be used in different genetic analyses (Supplemental Information 2). No evidence of linkage disequilibrium was found on the analyzed loci. We did not observe any loci out of Hardy-Weinberg equilibrium. Levels of expected heterozygosity $\left(\mathrm{H}_{\mathrm{E}}\right)$ ranged from medium to high for all markers (mean $\mathrm{H}_{\mathrm{E}}=$ 0.79 , and mean $\mathrm{H}_{\mathrm{O}}=0.72$ ). In the majority, there was no evidence of null alleles, but three loci (Spar05, Spar07, Spar013) showed significant frequencies of null alleles (above 15\%-Table 2).

Cross-species amplification showed differences for the twelve related species (Table 3). S. new species 3 presented the largest number of amplified microsatellites (8), followed by S. bakeri (7). S. mordax had the lowest number of amplified loci (4).

\section{Discussion}

Next Generation Sequencing allowed the project to obtain a large number of microsatellite loci for the $\mathrm{t} \bigcirc \mathrm{t}$ species. This method has been probed for several bat species, and it is becoming a standard method for acquiring specific molecular markers (McCulloch \& Stevens, 2011). Given the natural applicability of microsatellites to solve ecological questions, these molecular markers have emerged as a multipurpose indicator for ecological applications (Zane, Bargelloni, \& Patarnello, 2002; Selkoe \& Toonen, 2006). Its applicability spreads to different academic fields such as population genetics, behavioral ecology, genomics, phylogenies, etc.

Our microsatellites conformed to the normal standard measures (Balloux \& LugonMoulin, 2002). These indicators provide a straightforward approach for describing genetic variation due to the high level of existing alleles. Low allelic richness can affect accuracy 
162 in estimating population genetic parameters, leading to significant errors in assessing 163 genetic diversity of target populations (Bashalkhanov, Pandey \& Rajora, 2009). Here, we

164 present a novel set of microsatellite loci with the potential to estimate genetic diversity in a

165 non-model species. Standard measures for our microsatellites may have important

166 implications in the evolutionary biology of the target species, because they can be used to

167 develop conservation strategies for Neotropical bats. Highly informative microsatellites

168 have been used to assess genetic diversity in a broad range of bat populations and to 169 propose measures for conservation (i.e., Rossiter et al., 2000; Romero-Nava, León-

170 Paniagua \& Ortega, 2014; Korstian, Hale, \& Williams, 2015).

$171 \quad$ Amplified microsatellites for S. parvidens presented levels of polymorphism and

172 heterozygosity similar to those found in other bat species (i.e. Artibeus jamaicensis-

173 Ortega et al., 2002; Rhinolophus ferrumequinum—Dawson et al., 2004; Desmodus

174 rotundus-Piaggio, Johnston \& Perkins, 2008; Corynorhinus spp.-Lee, Howell \& Van Den

175 Bussche, 2011; Myotis spp.-Jan et al., 2012; Carollia castanea-Cleary, Waits \&

$176 \quad$ Hohenlohe, 2016).

Microsatellite markers are widely used to infer levels of genetic diversity in natural

178 populations. Molecular markers are not always developed for the target species and the

179 use of microsatellite loci from related species can be accurate. Ascertainment bias limited

180 the microsatellite-based amplification due to the particular selection of polymorphic

181 markers in the target species, plus the reduced sensitivity of the markers due to the

182 phylogenetic constrictions of the particular evolutionary traits of each sister species

183 (Crawford et al., 1998; Schlötterer, 2000; Li \& Kimmel, 2013). The bias leads to a lower 184 average allele length due to the phylogenetic restriction provided by the unique 
185 evolutionary history of each species ( $\mathrm{Li} \& \mathrm{Kimmel}, 2013)$. We tested the potential use of

186 our markers in related species, fo $\bigcirc$ ng multilocus heterozygosities inside the Sturnira

187 genus. This positive effect suggests using the developed markers to extrapolate genetic

188 diversity in future studies for this highly speciose genus, in which the past demographic

189 shared histories barely $\mathrm{P}$ the cross-species amplification consolidation.

190 Conclusions

191 We used Illumina Paired-Sequences to efficiently develop microsatellite loci for

192 Sturnira parvidens. We formed a genomic library to obtain 12 specific and polymorphic

193 microsatellites for this bat. Microsatellites showed high allelic richness per locus, showing

194 their effectiveness for further studies (i.e. population genetics, behavioral ecology, etc.).

195 Cross-species amplification was effective for the 12 related species, but with no positive 196 amplifications in several cases.

197 Acknowledgments

198 We are grateful for the supporting fieldwork provided by students of the Facultad de

199 Ciencias, UNAM (MZFC-M). We would like to thank the Field Museum of Natural

200 History, Chicago (FMNH); Louisiana State University, Lousiana State University,

201 Museum of Zoology, Baton Rouge (LSUMZ); Museo de Zoología de la Universidad de

202 Costa Rica, San José, Costa Rica (MZUCR); Museum of Texas Tech University, Lubbock

203 (TTU) for providing tissues from their collections. Particular special thanks go to Bruce D.

204 Patterson and Natalia Cortés-Delgado from FMNH; David Villalobos and Bernal

205 Rodríguez from MZUCR; Frederick H. Sheldon and Donna L. Dittmann from LSUMZ;

206 and Caleb D. Phillips from TTU for providing samples.

207 References 
Aljanabi S, Martinez, I. 1997. Universal and rapid salt extraction of high quality genomic DNA for PCR-based techniques. Nucleic Acid Research 25: 4692-4693.

Balloux F, Lugon-Moulin N. 2002. The estimation of population differentiation with microsatellite markers. Molecular Ecology 11:155-165.

Bashalkhanov S, Pandey M, Rajora OP. 2009. A simple method for estimating genetic diversity in large populations from finite sample sizes. BMC Genetics 10:84 DOI: 10.1186/1471-2156-10-84.

Castoe TA, Poole AW, de Koning APJ, Jones KL, Tomback DF, Oyler-McCance SJ, Fike JA, Lance SL, Streicher JW, Smith EN, Pollack DD. 2012. Rapid microsatellite identification from Illumina paired-end genomic sequencing in two birds and a snake. PLoS One 7:e30953.

Cleary KA, Waits LP, Hohenlohe PA. 2016. Development and characterization of fourteen novel microsatellite markers for the chestnut short-tailed fruit bat (Carollia castanea), and cross-amplification to related species. PeerJ 4:e2465; DOI: $10.7717 /$ peerj.2465.

Crawford AM, Kappes SM, Paterson KA, de Gortari MJ, Dodds KG, Freking BA, Stone RT, Beattie CW. 1998. Microsatellite evolution: testing the ascertainment bias hypothesis. Journal of Molecular Evolution 46:256-260.

Dawson DA, Rossiter SJ, Jones G, Faulkes CG. 2004. Microsatellite loci for the greater horseshoe bat, Rhinolophus ferrumequinum (Rhinolophidae, Chiroptera) and their cross-utility in 17 other bat species. Molecular Ecology Notes 4:96-100 DOI: 10.1046/j.1471-8286.2003.00580.x.

Evelyn MJ, Stiles DA. 2003. Roosting requirements of two frugivorous bats (Sturnira 
235

236

237

lilium and Artibeus intermedius) in fragmented Neotropical forest. Biotropica $35: 405-418$

Excoffier L, Laval G, Schneider S. 2003. Arlequin ver. 3.0: An integrated software package for population genetics data analysis. Evolutionary Bioinformatics Online $1: 47-50$.

Faircloth BC. 2008. MSTACOMMANDER: detection of microsatellite repeat arrays and automated, locus-specific primer design. Molecular Ecology Resources 8:92-94.

Gannon WL, Sikes RS, Animal Care and Use Committee of the American Society of Mammalogists. 2007. Guidelines of the American Society of Mammalogists for the use of wild mammals in research. Journal of Mammalogy 88:809-823.

Hernández-Canchola G, León-Paniagua L. Submitted. Historical and ecological processes promoting early diversification inside of the lowland Mesoamerican bat Sturnira parvidens (Chiroptera: Phyllostomidae).

Jan C, Dawson DD, Altringham JD, Burke T, Butlin RK. 2012. Development of conserved microsatellite markers of high cross-species utility in bat species (Vespertilionidae, Chiroptera, Mammalia). Molecular Ecology Resources 12:532548 DOI:10.1111/j.1755-0998.2012.03114.x.

Kalinowski ST, Taper ML, Marshall TC. 2007. Revising how the computer program CERVUS accommodates genotyping error increases success in paternity assignment. Molecular Ecology 16:1099-1106 DOI: 10.1111/j.1365294X.2007.03089.x.

Korstian JM, Hale AM, Williams DA. 2015. Genetic diversity, historic population size, and population structure in 2 North American tree bats. Journal of Mammalogy 
96:972-980.

255 Lee DN, Howell JM, Van Den Bussche RA. 2011. Development and characterization of 15 polymorphic tetranucleotide microsatellite loci for Townsend's big-eared bat (Corynorhinus townsendii) and cross amplification in Rafinesque's big-eared bat (Corynorhinus rafinesquii). Conservation Genetic Resources 4:429-433.

Lewis P, Zaykin D. 2001. Genetic data analysis: computer program for the analysis of allelic data. Version 1.0 (d16c). Available at http://lewis. eeb.uconn.edu/lewishome/software.html. (Accessed October 2016).

Li B, Kimmel M. 2013. Factors influencing ascertainment bias of microsatellite allele sizes: impact on estimates of mutation rates. Genetics 195:563-572.

McCulloch ES, Stevens RS. 2011. Rapid development and screening of microsatellite loci for Artibeus lituratus and their utility for six related species within Phyllostomidae. Molecular Ecology Resources 11:903-913.

Molinari J, Bustos XE, Burneo SF, Camacho MA, Moreno SA, Fermín G. 2017. A new polytypic species of yellow-shouldered bats, genus Sturnira (Mammalia: Chiroptera: Phyllostomidae), from the Andean and coastal mountain systems of Venezuela and Colombia. Zootaxa 4243(1): 75-96.

Olea-Wagner A, Lorenzo C, Naranjo E, Ortiz D, León-Paniagua L. 2007. Diversidad de frutos que consumen tres especies de murciélagos (Chiroptera: Phyllostomidae) en la selva Lacandona, Chiapas, México. Revista Mexicana de Biodiversidad 78:191200.

Ortega J, Maldonado JE, Arita HT, Wilkinson, G, Fleischer R. 2002. Characterization of microsatellite loci in the Jamaican fruit-eating bat Artibeus jamaicensis and cross- 
species amplification. Molecular Ecology Notes 2: 462-464.

278 Piaggio AJ, Johnston JJ, Perkins SL. 2008. Permanent genetic resources: development of polymorphic microsatellite loci for the common vampire bat, Desmodus rotundus (Chiroptera: Phyllostomidae). Molecular Ecology Resources 8:440-442.

281

282

283
Romero-Nava C, León-Paniagua LS, Ortega J. 2014. Microsatellites loci reveal heterozygosis and population structure in vampire bats (Desmodus rotundus) (Chiroptera: Phyllostomidae) of Mexico. Revista de Biologia Tropical 52:659-669. structure in the endangered greater horseshoe bat Rhinolophus ferrumequinum. Molecular Ecology 9:1131-1135.

Rousset F. 2008. Genepop'007: a complete reimplementation of the Genepop software for Windows and Linux. Molecular Ecology Resources 8:103-106.

Selkoe KA, Toonen RJ. 2006. Microsatellites for ecologists: a practical guide to using and evaluating microsatellite markers. Ecology Letters 9:615-629.

Schlötterer C. 2000. Evolutionary dynamics of microsatellite DNA. Chromosoma 109:365-371.

van Oosterhout C, Hutchinson WF, Wills DPM, Shipley P. 2004. MICRO-CHECKER: software for identifying and correcting genotyping errors in microsatellite data. Molecular Ecology Notes 4:535-538.

Velazco PM, Patterson BD. 2013. Diversification of the yellow-shouldered bats, genus Sturnira (Chiroptera, Phyllostomidae), in the New World tropics. Molecular Phylogenetics and Evolution 68:683-698.

Velazco PM, Patterson BD. 2014. Two new species of yellow-shouldered bats, genus 

western Ecuador. ZooKeys 402:43-66.

302 Villalobos F, Valerio AA. 2002. The phylogenetic relationships of the bat genus Sturnira Gray, 1842 (Chiroptera: Phyllostomidae). Mammalian Biology 67:268-275.

304 Zane L, Bargelloni L, Patarnello T. 2002. Strategies for microsatellite isolation: a review. Molecular Ecology 11:1-6.

306 
307

308

309

310

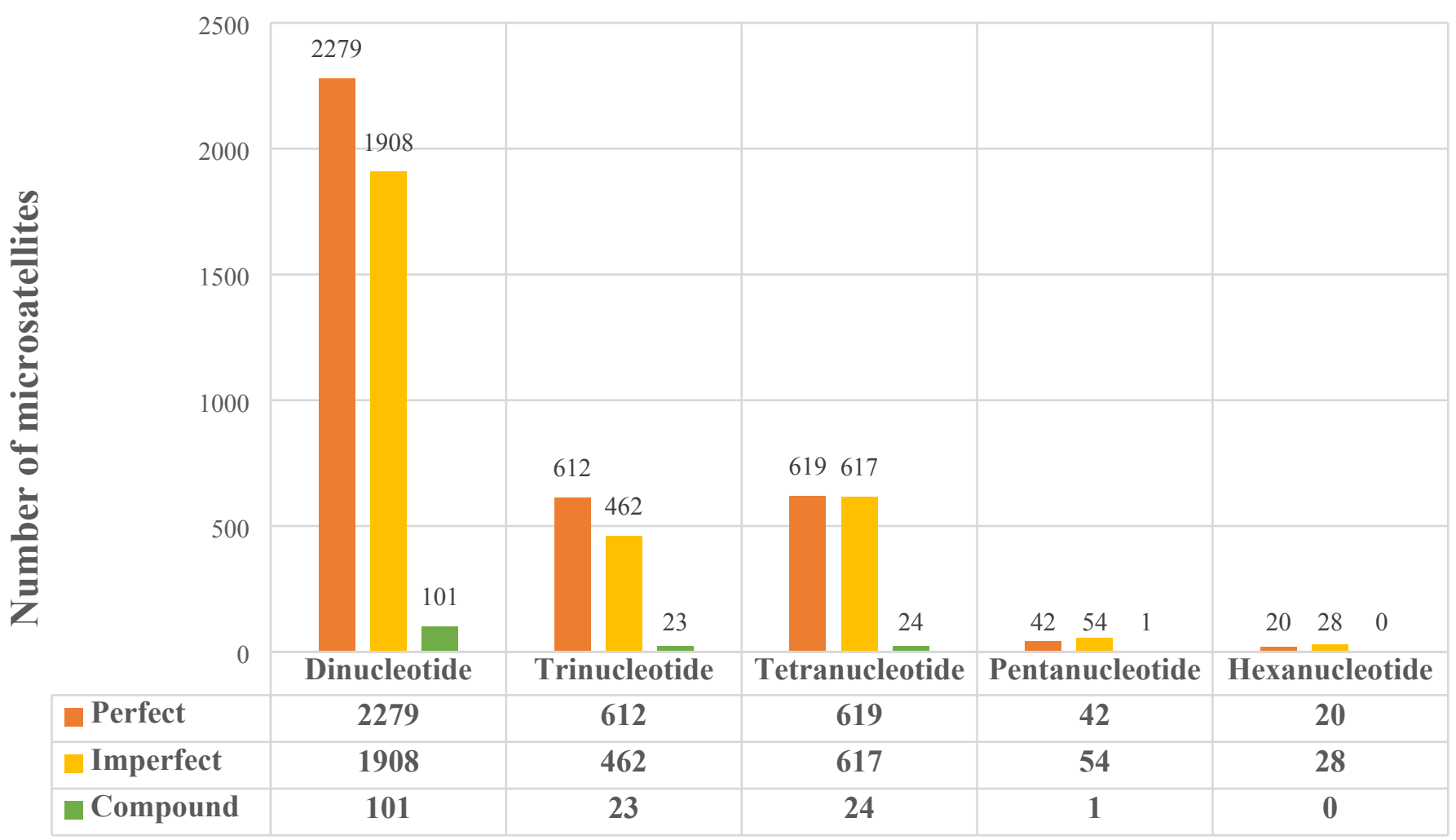

Figure 1. - Potentially am 2 d loci (PAL's) with positive microsatellites found in the enriched library. Perfect, imperfect and compound loci separated out for dinucleotide to hexanucleotide microsatellite forms.
311

312

313

314

315

316

317

318

319

320

321 
324

325

326

327

328 
Table 1. - Primer sequences and characteristics of the 14 microsatellite loci isolated for

331 Sturnira parvidens.

332

\begin{tabular}{|c|c|c|c|c|}
\hline Locus & Primer (Forward) (5-3') & Primer (Reverse) (5-3') & Motif & $\begin{array}{c}\text { Anneali } \\
\text { ng } \\
\mathbf{T}\left({ }^{\circ} \mathbf{C}\right)\end{array}$ \\
\hline Spar0 & 6 FAM- & CССАТАСТTСТСССТCACAGC & AAAG(9 & 58 \\
\hline 1 & TGCCCTGAAGAACTTTGAGC & & 2) & \\
\hline Spar0 & 6 FAM- & TTCTTTATGCCCTTTGCTCTAGG & AAAG(1 & 60 \\
\hline 2 & AGAAAGAAAGGGAGGGCGG & & 04) & \\
\hline Spar0 & 6 FAM- & AAGCAGTTCCCATCACATGC & $\operatorname{ATC}(33)$ & 56 \\
\hline 5 & TGCCTGCCTAGTCTGTCACC & & & \\
\hline Spar0 & 6-FAM- & GAATAATGGGAATACCAGAATAA & TTC(30) & $x$ \\
\hline 6 & CCTGGGATGAAGTTTCTGACG & GACG & & \\
\hline Spar0 & 6 FAM- & CCCAGATTGCTGCCTCTCC & TGC(30) & 56 \\
\hline 7 & CTCCCACGGACAATCAACG & & & \\
\hline Spar0 & 6 FAM- & GGATGTGTTGTGAAGATTGTGC & ATT(30) & 56 \\
\hline 8 & GGAGTCTCCTTCATTAAGTGCC & & & \\
\hline Spar0 & 6 FAM- & CCСАTCATACССТССТTTGC & $\mathrm{AC}(44)$ & 60 \\
\hline 9 & AAGTCCATTTCAAGGCTGGG & & & \\
\hline Spar0 & 6 FAM- & ACTGTAGCCACTTCCCTGCC & $\mathrm{AC}(44)$ & 60 \\
\hline 10 & TCTGGCCTGAGGTATTTGGG & & & \\
\hline Spar0 & 6 FAM-AAGCCACTGCCTTGTGCC & GACTCTCTGGACATTGGCCC & $\mathrm{TC}(44)$ & 60 \\
\hline 11 & & & & \\
\hline Spar0 & 6 FAM- & CTGTCATTGCATGGGTTGG & $\mathrm{AC}(44)$ & 60 \\
\hline 12 & $\begin{array}{l}\text { GGGAGTGAATGAGAAAGATAAA } \\
\text { GTCC }\end{array}$ & & & \\
\hline Spar0 & 6 FAM- & TGAATGTATCCTAGGGCGAGC & $\mathrm{AC}(42)$ & 60 \\
\hline 13 & AAAGATTCCTGGAGATCATACCC & & & \\
\hline Spar0 & 6-FAM- & AGTCCTGGCAGGTGTGTCC & $\mathrm{TC}(32)$ & $x$ \\
\hline 14 & TTTCTCTCACTGTCTAACTCTGCC & & & \\
\hline Spar0 & 6 FAM- & CCGTTCTAGGCTCAGTTTCC & $\operatorname{ATT}(36)$ & 60 \\
\hline 30 & $\begin{array}{l}\text { AATGGCACCATATTATTCTACAT } \\
\text { AGG }\end{array}$ & & & \\
\hline Spar0 & 6 FAM- & GAGTTTCAGGGAGTATTTCAGTGC & ATC(33) & 60 \\
\hline & $\begin{array}{l}\text { GACTGAGACAATTGCTTGAGATA } \\
\text { GC }\end{array}$ & & & \\
\hline
\end{tabular}


334 Table 2. - Diagnostic characteristics of selected microsatellites. Number of alleles, size

335

336

\begin{tabular}{|c|c|c|c|c|c|c|c|c|}
\hline Locus & $\begin{array}{c}\text { GenBank } \\
\text { Accession } \\
\text { Number }\end{array}$ & $\begin{array}{c}\text { No. } \\
\text { alleles }\end{array}$ & $\begin{array}{l}\text { Size } \\
\text { range } \\
\text { (bp) }\end{array}$ & PI & Ho & He & HWE & $\begin{array}{c}\text { Null } \\
\text { alleles }\end{array}$ \\
\hline Spar01 & KY645946 & 7 & $132-236$ & 0.7098 & 0.941 & 0.761 & 0.08 & $x$ \\
\hline Spar02 & KY 645947 & 6 & $130-222$ & 0.6455 & 0.765 & 0.692 & 0.08 & $x$ \\
\hline Spar05 & KY645948 & 6 & $124-226$ & 0.6069 & 0.412 & 0.699 & 0.05 & $\checkmark$ \\
\hline Spar07 & KY645949 & 10 & $121-226$ & 0.8028 & 0.824 & 0.865 & 0.18 & $\checkmark$ \\
\hline Spar08 & KY645950 & 11 & $130-382$ & 0.8052 & 0.800 & 0.860 & 0.13 & $x$ \\
\hline Spar09 & KY645951 & 13 & $134-230$ & 0.8864 & 0.875 & 0.933 & 0.11 & $x$ \\
\hline Spar010 & KY645952 & 12 & $132-236$ & 0.8698 & 0.882 & 0.919 & 0.08 & $x$ \\
\hline Spar011 & KY645953 & 8 & $124-222$ & 0.8125 & 0.588 & 0.863 & 0.12 & $x$ \\
\hline Spar012 & KY 645954 & 8 & $128-214$ & 0.7068 & 0.750 & 0.772 & 0.08 & $x$ \\
\hline Spar013 & KY645955 & 10 & $124-220$ & 0.8577 & 0.500 & 0.867 & 0.05 & $\checkmark$ \\
\hline Spar030 & KY645957 & 6 & $133-169$ & 0.7088 & 0.741 & 0.735 & 0.08 & $x$ \\
\hline Spar040 & KY645958 & 6 & $124-190$ & 0.6721 & 0.662 & 0.669 & 0.08 & $x$ \\
\hline
\end{tabular}

range, polymorphic information (PI), observed heterozygosity (Ho), expected heterozygosity (He), Hardy-Weinberg equilibrium (HWE), and null alleles.
337

338

339

340

341

342 
345 Table 3. - Cross-species amplifications of the designed primers for S. parvidens. We

346 followed same PCR conditions in the twelve related species. ( $\mathbf{X}$ ) no positive amplification,

$347\left(\checkmark\right.$ p) positive polymorphic amplification, $\left(\checkmark\right.$ m) positive monomorphic amplification, $\left(\checkmark^{*}\right)$

348 polymorphism not proven because PCR conditions were not standardized.

349

350

351

352

353

354

355

356

357

358 
Locus

S. hondurensis

S. burtonlimi

S. oporaphilum

S. mordax

363

364

\begin{tabular}{ccccc} 
& $(\mathbf{n}=\mathbf{3})$ & $(\mathbf{n}=\mathbf{3})$ & $(\mathbf{n}=\mathbf{1})$ & $(\mathbf{n}=\mathbf{2})$ \\
\hline Spar01 & $\times$ & $\checkmark \mathrm{p}$ & $\mathbf{X}$ & $\mathbf{X}$ \\
\hline Spar02 & $\checkmark \mathrm{p}$ & $\times$ & $\checkmark^{*}$ & $\times$ \\
\hline Spar05 & $\checkmark \mathrm{p}$ & $\checkmark \mathrm{p}$ & $\checkmark^{*}$ & $\checkmark^{*}$ \\
\hline Spar07 & $\times$ & $\times$ & $\times$ & $\times$ \\
\hline Spar08 & $\checkmark^{*}$ & $\checkmark \mathrm{p}$ & $\checkmark^{*}$ & $\checkmark \mathrm{p}$ \\
\hline Spar09 & $\times$ & $\checkmark \mathrm{p}$ & $\checkmark^{*}$ & $\checkmark^{*}$ \\
\hline Spar010 & $\times$ & $\checkmark{ }^{*}$ & $\checkmark^{*}$ & $\times$ \\
\hline Spar011 & $\checkmark *$ & $\checkmark \mathrm{p}$ & $\checkmark^{*}$ & $\checkmark \mathrm{p}$ \\
\hline Spar012 & $\checkmark \mathrm{m}$ & $\times$ & $\checkmark^{*}$ & $\times$ \\
\hline Spar013 & $\times$ & $\times$ & $\checkmark^{*}$ & $\times$ \\
\hline
\end{tabular}




\begin{tabular}{|c|c|c|c|c|c|c|c|}
\hline $\begin{array}{c}S . \\
\text { tildae } \\
(\mathrm{n}=1)\end{array}$ & $\begin{array}{c}S . \\
\text { erythromos } \\
(\mathrm{n}=1)\end{array}$ & $\begin{array}{c}S . \\
\text { magna } \\
(\mathrm{n}=1)\end{array}$ & $\begin{array}{c}S . \\
\text { bogotensis } \\
(\mathrm{n}=1)\end{array}$ & $\begin{array}{c}S . \\
\text { newspecies_3 } \\
(\mathrm{n}=\mathbf{3})\end{array}$ & $\begin{array}{l}\text { S. luisi } \\
(\mathrm{n}=3)\end{array}$ & $\begin{array}{c}S . \\
\text { lilium } \\
(\mathrm{n}=\mathbf{3})\end{array}$ & $\begin{array}{c}S . \\
\text { bakeri } \\
(\mathrm{n}=2)\end{array}$ \\
\hline$x$ & $x$ & $x$ & $x$ & $\checkmark p$ & $x$ & $\checkmark *$ & $\checkmark *$ \\
\hline$x$ & $x$ & $\checkmark *$ & $x$ & $\checkmark *$ & $x$ & $x$ & $\checkmark *$ \\
\hline$\sqrt{ } *$ & $x$ & $\checkmark *$ & $x$ & $\checkmark *$ & $\checkmark *$ & $\sqrt{ } *$ & $x$ \\
\hline$x$ & $x$ & $x$ & $x$ & $\checkmark p$ & $x$ & $x$ & $\checkmark p$ \\
\hline$\sqrt{ } *$ & $\checkmark^{*}$ & $x$ & $\checkmark *$ & $\checkmark p$ & $\checkmark *$ & $\checkmark *$ & $\checkmark p$ \\
\hline$\sqrt{ } *$ & $\checkmark *$ & $x$ & $\checkmark *$ & $\checkmark p$ & $\checkmark *$ & $\checkmark *$ & $\checkmark p$ \\
\hline$\sqrt{ } *$ & $\checkmark *$ & $\checkmark *$ & $\sqrt{ } *$ & $\checkmark p$ & $\checkmark *$ & $\checkmark p$ & $\checkmark p$ \\
\hline$\checkmark *$ & $\checkmark *$ & $\checkmark *$ & $\checkmark *$ & $\checkmark *$ & $\checkmark p$ & $\sqrt{ } *$ & $\checkmark *$ \\
\hline$\checkmark *$ & $\sqrt{*}$ & $\checkmark *$ & $\checkmark *$ & $x$ & $x$ & $x$ & $x$ \\
\hline
\end{tabular}

Table 3.- Continuation.....

367 


\begin{tabular}{llllllll}
\hline$*$ & $\checkmark$ & $\checkmark^{*}$ & $\checkmark^{*}$ & $\times$ & $\times$ & $\times$ & $\times$
\end{tabular}

